\title{
¿De qué hablamos cuando hablamos de comunicación, relación, participación, compromiso e involucramiento de las familias con la escuela?
}

What does it mean when we talk about families' communication, relationship, participation, commitment and involvement with the school

\author{
NICOL ACUÑA ECHEVERRÍA \\ nicol.acuna1501@alumnos.ubiobio.cl \\ BÁRBARA CONCHA CONTRERAS \\ barbara.concha1502@alumnos.ubiobio.cl \\ BÁRBARA DE LA FUENTE CONTRERAS \\ barbara.de1501@alumnos.ubiobio.cl \\ ROSA MEDINA GATICA \\ rosa.medina1501@alumnos.ubiobio.cl \\ Profesoras de Educación Básica \\ Universidad del Biobío, Chile \\ HÉCTOR CÁRCAMO VÁSQUEZ \\ hcarcamo@ubiobio.cl \\ Académico Departamento de Ciencias Sociales \\ Universidad del Biobío, Chile
}

\section{RESUMEN}

Este ensayo pretende hacer una distinción conceptual entre comunicación, participación, relación y compromiso para esclarecer el significado de estos conceptos y así aportar nueva información a las investigaciones sobre la temática relacionada con la familia y la escuela. En tal sentido, ambos conceptos conforman el involucramiento, que es imprescindible en la alianza que se presenta entre los agentes de la familia y escuela, puesto que generan un impacto positivo en la educación de los alumnos.

Palabras clave: familia, escuela, involucramiento, relación, participación, comunicación, compromiso. 


\section{ABSTRACT}

This essay aims to make a conceptual distinction between communication, participation, relationship and commitment to clarify the meaning of these concepts and thus provide new information about the family and family relationship. Emphasizing, also that these concepts make up the involvement, which is considered essential in the partnership that is presented between the agents of the family and the school, the position that generates a positive impact on the education of students and schools.

Key words: family, school, involvement, teacher beliefs, relationship, participation, communication, commitment.

\section{INTRODUCCIÓN}

En la sociedad se reconocen dos grandes agentes del proceso de socialización de niños: la familia y la escuela; ambos están encargados de transmitir valores, actitudes y conocimientos que forjan la personalidad y el desarrollo íntegro de las personas. Por ello, es fundamental que se genere una unión o alianza entre ambos agentes para lograr un desarrollo interpersonal eficaz en los diferentes ámbitos que se presentan en la vida.

Varios estudios realizados en Chile y en España (Razeto, 2016; De León, 2011; Domínguez, 2010), coinciden en que la familia y la escuela pueden tener diferentes intereses, pero es imprescindible encontrar un punto en común (o de relación) para lograr aportes significativos en el desarrollo de los niños.

Al respecto, tanto la familia como la escuela deben realizar la labor educativa de manera conjunta y no diferenciada la una de la otra, siendo conscientes del rol que cumplen para enriquecer el proceso de socialización de los niños. Esto, resulta importante para alcanzar buenos resultados académicos y un desarrollo íntegro del individuo, razón por la que es necesario incrementar la comunicación, la relación, la participación y el compromiso, es decir, el involucramiento de las familias con la escuela.

Considerando los aspectos mencionados en líneas anteriores, surgen interrogantes tales como ¿qué se entiende por comunicación, relación, 
participación, compromiso e involucramiento?, ¿son conceptos similares o aluden a diferentes significados? A ellas, se les tratará de dar respuestas en el presente ensayo, con la finalidad de aportar nuevas informaciones para el desarrollo de futuras investigaciones con respecto a la relación existente entre familia y escuela.

\section{Diferenciación conceptual}

Es necesario esclarecer los conceptos que conforman el involucramiento, debido a que aparentan ser conceptos iguales, pero no tienen el mismo significado. Estas nociones son: comunicación, relación, participación y compromiso.

\section{La comunicación}

Frías (2000) sostiene que la comunicación es "la transmisión de un mensaje de una persona o grupo a otro, lo que requiere de la existencia de voluntad de interacción entre ambas partes, es decir, que se cree un proceso de influencia mutua y recíproca [...] entre los comunicantes". Asimismo, Berelson y Steiner (1964) señalan que esta "consiste en la transmisión de información, ideas, emociones, habilidades, mediante el empleo de signos y palabras". Dicho de otro modo, la comunicación es la interacción entre dos o más sujetos (emisor y receptor) que buscan transmitir en el contexto educativo (escuela y familia) una información con un objetivo, a través de diferentes canales y con códigos específicos.

Garreta y Maciá (2017) plantean que la comunicación entre la familia y la escuela debe ser unidireccional y bidireccional, generando una reciprocidad con el objetivo de potenciar la relación entre ambos agentes, por lo que este concepto se considera una herramienta fundamental para incrementar los intereses que tengan en común las familias y los centros educativos.

Al respecto, para que se intensifiquen los intereses de la familia con la escuela, y viceversa, debe existir una correspondencia de la información, es decir, que se comprenda lo que la institución educativa -específicamente los docentes- quiere decir y que, a la vez, los profesores vislumbren lo que la familia del estudiante le comunica.

Garreta y Maciá (2017) señalan que existen dos tipos de canales de comunicación que son los encargados de mantener esta unión entre la familia y la 
escuela: tradicionales y tecnológicos. Los canales de comunicación tradicionales pueden ser individuales o grupales. En el caso de los canales individuales (profesorapoderado) se encuentran: las tutorías con la familia, entrevistas personales y agenda escolar; entre los canales grupales (profesor-apoderados) destacan: las circulares, notas dirigidas a las familias y las reuniones grupales.

Los canales de comunicación tecnológicos también pueden ser individuales o grupales. De esa forma, las plataformas digitales, el correo electrónico y el teléfono forman parte de los canales individuales; $y$, entre los grupales se encuentran: las páginas web y blog.

Maciá (2016) agrega que los canales de comunicación tecnológicos son utilizados principalmente por los centros educativos con el fin de brindar información importante de los estudiantes a las familias, por lo tanto, la información resulta ser de carácter unidireccional, pues el mensaje a entregar viaja en un solo sentido, lo que provoca la pérdida de la reciprocidad de la comunicación que se espera tener en el contexto educativo. Es decir, las familias se limitan a ser solamente receptores del mensaje.

Lo anterior constituye un aspecto preocupante y representa un desafío para los establecimientos educacionales, dado que, según diversos autores, ellos son los principales responsables de la promoción de una comunicación estable y fluida entre las familias y las escuelas, cuya característica sea la reciprocidad (Cerletti, 2010; Garreta, 2016; Gubbins, 2016).

\section{La relación}

La relación hace referencia al vínculo existente entre familia y escuela. El Diccionario de la Real Academia Española define el término como la: "Conexión, correspondencia de algo con otra cosa" (2017), es decir, se alude a un enlace 0 unión de un elemento, persona o cosa con otro. En esta ocasión, el vínculo que surge entre la familia y la escuela.

En el mismo sentido Vigo, Dieste y Julve (2017) señalan: "cuando las escuelas trabajan conjuntamente con las familias, los hijos incrementan su rendimiento académico y, además, el centro mejora su calidad educativa" (p. 149). Es por ello que, hacer posible esta relación es fundamental para el desarrollo académico de los estudiantes, aunque -como indican autores como Jofarov (2015) y Alonso 
(2015) - el incremento de los resultados académicos no se da por la sola existencia de una relación entre los agentes, sino por los tipos de relación específicas en las que intervienen otros factores tales como las condiciones materiales, el capital cultural familiar y la disposición de los establecimientos educativos por reconocer e integrar este último (Múñoz, Agajan, Cea y Luengo , 2013).

Asimismo, al estar los padres más implicados en la educación de sus hijos, estos generan mayores vínculos de confianza y potencian la formación valórica.

\section{La participación}

La "Política de Participación de Padres, Madres y Apoderados/as en el Sistema Educativo", elaborado por el Ministerio de Educación (2002), señala lo siguiente: "Se entiende en forma amplia la participación como: un proceso de involucramiento de personas y grupos en cuanto sujetos y actores en las decisiones y acciones que los afectan a ellos o a su entorno." (p. 29). Es necesario añadir que, la acción de participar atiende a un interés, una opción y una ideología personal de parte de las personas involucradas. Es importante aclarar que, en la actualidad esa normativa ya no está vigente, debido a una actualización que dio paso a la denominada "Política de Convivencia Escolar" (Ministerio de Educación, 2015). Al respecto, en esta última, es posible apreciar una vinculación más profunda de las familias, al ser consideradas parte de la "comunidad educativa"; a diferencia de la política caducada, donde se mencionaba a la familia como un agente fundamental en la educación, pero no aliado a los centros educativos.

La participación también se entiende como "aquello que permite en mayor medida que cada miembro del grupo despliegue sus atributos y potencialidades individuales y haga aportes decisivos a la vida del conjunto" (Amnistía Internacional, 1996, p. 38) (citado en Corona y Morfín, 2001), mientras que el Diccionario de la Real Academia Española concibe la participación como: "tomar parte en algo" (2017).

Es decir, es posible comprender la participación como una manera de pertenecer a la sociedad, dando a conocer opiniones e intereses personales. Aplicando lo anterior en un marco educativo, se comprende que las familias, junto a la escuela, deben ser una potencia en la que se aprecie un aporte, exista la mutua colaboración, y en donde la decisiones que se tomen sean compartidas y en beneficio del proceso educativo de los hijos. 
Del mismo modo, Vigo, Dieste y Julve (2017) indican: "el concepto de participación de las familias en los centros escolares no goza de una definición 0 un significado unívoco, aunque existe cierto consenso respecto a los términos con los que se puede caracterizar: colaborar, involucrar, gestionar, intervenir, ayudar, implicar" (p. 49).

De acuerdo con esa definición, se puede afirmar que la participación tiene niveles de implicación que categorizan la participación de las familias en los centros educativos, tal como lo plantea Epstein (2013).

Siguiendo ese lineamiento, Vogels (2002) -citado en Colás y Contreras (2013)realiza una propuesta para categorizar el nivel de implicación de las familias en la escuela, considerando la implicación en una escala ascendente. Vogels las categoriza en: consumidores, clientes, participantes y socios, siendo los "socios" quienes alcanzan la mayor implicación en el proceso educativo de sus hijos y los "clientes" quienes menos se implican en la formación de los hijos.

\section{El compromiso}

Al hablar de compromiso, O'reilly y Chatman (1986) -citado en Juaneda y González (2007)- lo entienden como "vínculo psicológico sentido por una persona hacia una organización, que reflejará el grado con el cual el individuo interioriza 0 adopta características o perspectivas de la organización" (p. 3592).

Del mismo modo, Becker (1960) -citado en Juaneda y González (2007)- afirma que: "el compromiso surge cuando una persona, por la realización de inversiones para el mantenimiento de ciertos intereses, permanece con una consistente línea de actuación" (p. 3591). Es decir, el concepto nombrado con anterioridad demuestra el grado de interiorización entre dos agentes (familia y escuela), que adoptan características e intereses similares y actúan en una sola línea.

El compromiso que tengan las familias con la escuela de sus hijos resulta importante, debido a la implicancia de este en diferentes aspectos en la etapa escolar de niños, tales como en los resultados académicos, en el desarrollo de las habilidades sociales, en el comportamiento y en la vida posterior al proceso de escolarización. La familia, a su vez, al comprometerse con la escuela, asume ciertos roles: de sostenedores, innovadores, facilitadores, modelos, personas que 
toman decisiones, colaboradores y cocreadores. Esos roles serán visibles en el proceso educativo de sus hijos (Argibay y Arias, 2016).

\section{Involucramiento en el contexto educativo}

Esclarecidos los conceptos mencionados en párrafos anteriores, es posible comprender significativamente el concepto de involucramiento dentro del contexto educativo.

Arguedas (2010) se refiere a este como "las actitudes de las estudiantes y los estudiantes hacia el colegio, sus relaciones interpersonales dentro de la institución y su disposición hacia el aprendizaje" (p. 64). En otras palabras, se entiende que los alumnos dentro de la comunidad educativa realizan actividades escolares y extraescolares, sintiéndose aceptados por los miembros de la institución y pertenecientes a esta.

Desde la perspectiva del involucramiento de las familias en la escuela, se alude al compromiso y participación que tienen los padres, madres 0 apoderados con la institución escolar de sus hijos, entendiendo que tanto el compromiso como la participación benefician el éxito escolar. Así lo sostiene Coleman (1996) (citado en Razeto, 2016), quien destaca que la influencia de la familia no solo se restringe a su nivel económico, sino también al apoyo educativo que esta puede aportar a la formación de sus hijos.

Razeto (2016) agrega que el involucramiento es un desafío para los centros educativos, puesto que compete a todo su equipo pedagógico, destacando el rol que deben asumir los docentes, quienes son los más próximos a la realidad de los estudiantes. El autor enfatiza la importancia que se le da al involucramiento, en los tiempos y espacios escolares, considerando a este como un factor potencial en el éxito escolar de los niños.

Por otra parte, los conceptos descritos anteriormente (comunicación, relación, participación y compromiso) hacen referencia a la colaboración de los individuos entre sí (familia y escuela) y al hecho de que las decisiones que toma uno de estos agentes repercute en su entorno y en quienes conviven en él, estableciendo así un vínculo entre ellos. 


\section{Tabla 1}

Acerca del concepto de involucramiento y sus dimensiones constitutivas.

\begin{tabular}{ll}
\hline Involucramiento & \\
\hline Actuar recíproco entre los agentes familia y escuela, donde las decisiones que tome \\
cada parte influye en su entorno y en quienes forman parte de él. \\
Esta conceptualización se conforma por las siguientes subcategorías: comunicación, \\
relación, participación y compromiso. \\
\hline Comunicación & $\begin{array}{l}\text { Para efecto de esta investigación, el concepto comunicación se } \\
\text { entenderá como la transmisión de información entre la escuela y } \\
\text { las familias, que se manifiesta mediante canales (tradicionales y } \\
\text { tecnológicos). }\end{array}$ \\
\hline Relación & $\begin{array}{l}\text { Para efectos de esta investigación, el concepto de relación se en- } \\
\text { tenderá como el vínculo preestablecido entre las familias con la } \\
\text { escuela, desde que las familias ingresan a sus hijos al sistema } \\
\text { escolar. }\end{array}$ \\
\hline Participación & $\begin{array}{l}\text { Para efecto de esta investigación, el concepto de participación se } \\
\text { entenderá como el actuar colaborativo de las familias en la comu- } \\
\text { nidad educativa. } \\
\text { La participación se categoriza según niveles, siendo el de mayor } \\
\text { alcance: el involucramiento. }\end{array}$ \\
\hline Compromiso & $\begin{array}{l}\text { Para efecto de esta investigación, el concepto de compromiso se } \\
\text { entenderá como el sentimiento de pertenencia, que produce un } \\
\text { acto consciente, voluntario y de cooperación de las familias hacia } \\
\text { la escuela. }\end{array}$ \\
\hline
\end{tabular}

\section{CONCLUSIONES}

Los conceptos mencionados a través de este análisis tienden a ser confundidos o vistos como sinónimos, pues se pueden relacionar entre sí, no obstante, al definirlos individualmente podemos apreciar notables diferencias en sus significados. Esto, es necesario conocerlo para no tergiversar la información y facilitar la distinción de cada uno de ellos en investigaciones futuras, y por sobre todo, hacia los protagonistas del proceso de enseñanza: profesores. 
A partir de la evidencia recogida -y una vez comprendidos los conceptos (comunicación, relación, participación y compromiso)-, es posible establecer una conexión y distinción conceptual de estos, así como también entender que el involucramiento se conforma por los mencionados términos. De manera que, esta diferenciación aclare el significado del involucramiento en nuevas investigaciones, sin caer en confusión de los conceptos mencionados.

En todo caso, es necesario abrir una agenda de investigación que permita seguir nutriendo el conocimiento en esta materia. Tal como lo indica Jofarov (2015), la literatura internacional pone de manifiesto una amplia gama de beneficios que lleva consigo el involucramiento parental en el proceso de escolarización de niños, no obstante, no existe un consenso con respecto a la definición más adecuada para aludir a ese término.

Asimismo, contextualizando lo referido al ámbito educativo, se destaca lo imprescindible que es el involucramiento de las familias en el proceso de escolarización de sus hijos y la incidencia que conlleva en los resultados académicos que estos presenten, forjando así una educación integral y centros educativos felices. Situación que pone de manifiesto la tendencia de entender al involucramiento como un trabajar juntos por el cumplimiento de objetivos, objetivos que, por cierto, siempre son definidos y priorizados desde la escuela y las administraciones educativas centrales.

Precisamente ese aspecto llama nuestra atención, pues autores como Cárcamo (2015), Gubbins (2016), Razeto (2016) afirman que esta implicación parental representa una oportunidad de mejora no solo en cuanto a la performance educativa de niños, sino también una oportunidad para fortalecer la democracia y la gobernanza escolar, mediante la promoción de prácticas participativas de naturaleza dialógica, tal como lo plantea Schilling (2015).

Sin lugar a dudas, un abordaje de la temática relativa al involucramiento parental, contribuirá de forma significativa a la comprensión del fenómeno de la relación familias-escuelas, relevando el papel de cada uno de los agentes implicados en la mejora de la calidad educativa en el contexto nacional en sus diferentes niveles: preescolar, básica y media. Asimismo, la necesaria profundización teóricoconceptual, en torno al involucramiento parental educativo, abre un universo de oportunidades dirigidas a mejorar los procesos de formación inicial docente, mediante la problematización de temáticas fundamentales para cimentar una relación dialógica entre quienes componen las comunidades escolares. 


\section{REFERENCIAS BIBLIOGRÁFICAS}

ALONSO, C. (2015). "Familia, escuela y clases social: sobre los efectos perversos de la implicación familiar". RASE, 7, 2, 395-409).

ARGIBAY, L., ARIAS, M. (2016). "El Compromiso de la familia en la educación". En Durand, J. Corengia, A. \& Urrutia, M. (eds.). Gestionar Instituciones Educativas Socialmente Responsables: Aprender, Servir, Innovar. Buenos Aires, Argentina: Teseo, 2016.

ARGUEDAS NEGRINI, I. (2010). "Involucramiento de las estudiantes y los estudiantes en el proceso educativo". Revista Iberoamericana sobre Calidad, Eficacia y Cambio en Educación, pp. 64. Recuperado de: http:// www.redalyc.org/articulo.oa? id $=55113489005$.

BERELSON, B. \& STEINER, G. A. (1964). Comportamiento humano: un inventario de los hallazgos científicos. Nueva York: Harcourt, Brace \& World, pp. 712.

CÁRCAMO, H. (2013). "La familia como enemigo: imágenes que los futuros titulados en maestro de primaria de una universidad pública de Madrid poseen sobre la relación familia-escuela en un contexto multicultural". Si somos americanos, XV, 2, 41-65.

CERLETTI, L. B. (2010). "Familias y escuelas: Aportes de una investigación etnográfica a la problematización de supuestos entorno a las condiciones de escolarización infantil y la categoría familia". Intersecciones en Antropología, 11, 185-198.

COLÁS BRAVO, P. Y CONTRERAS ROSADO, J. A. (2013). "La participación de las familias en los centros de educación primaria". Revista de Investigación Educativa, 31(2), pp. 485-499.

CORONA CARAVEO, Y.; Y, MORFIN STOOPEN, M. (2001). Diálogo de saberes sobre participación infantil. Edit. Universidad Autónoma Metropolitana, primera edición, pp. 38. 
DE LEÓN SÁNCHEZ, B. (2011). La relación familia-escuela y su repercusión en la autonomía y responsabilidad de los niños/as. XII Congreso Internacional de Teoría de la Educación. Barcelona: Universidad de Barcelona. Recuperado de https://extension.uned.es/archivos_publicos/webex actividades/5385/repercusiones8.pdf

DOMÍNGUEZ, S. (2010). "La Educación, cosa de dos: La escuela y la familia". Revista Digital para Profesionales de la Enseñanza. Recuperado de: https://www.feandalucia.ccoo.es/ docu/p5sd7214.pdf

EPSTEIN, J. (2013). "Family, school, community engagement, and partnerships: an imperative for K-12, and Colleges of Education in the development of twenty-first-century educators". Teaching Education, 24(2), 115-118.

FRIAS AZCÁRATE, R. (2000). "Una aproximación al concepto comunicación y sus consecuencias en la práctica de las instituciones". Nómadas. Critical Journal of Social and Juridical Science, pp. 1578-6730. Recuperado de: http://www. redalyc.org/articulo.oa?id=18100103

GARRETA, J. (Coord.) (2017). Familias y escuelas: discursos y prácticas sobre la participación en la escuela. Madrid, España. Ediciones Pirámide.

GARRETA, J. (2016). "Las asociaciones de madres y padres en los centros escolares de Cataluña: puntos fuertes y débiles". Revista Electrónica Interuniversitaria de Formación del Profesorado, 19(1), 47-59.

GARRETA, J. Y MACIÁ, M. (2017). "La comunicación familia-escuela". En Garreta, J. (Coord.) Familias y escuelas: discursos y prácticas sobre la participación en la escuela, pp. 71 - 98. Madrid, España: Ediciones Pirámide.

JAFAROV, J. (2015). "Factors affecting parental involvement in education: tanalysis of literature". Khazar Journal of Humanities and Social Sciencies, 18(4), 35-44. 
JUANEDA, E., y GONZÁLEZ, L. (2007). Definición, antecedentes y consecuencias del compromiso organizativo. España: Universidad de la Rioja, pp. 3591-3592. Recuperado de: https://dialnet.unirioja.es/descarga/ articulo/2234965.pdf

MACIÀ, M. (2016). "La comunicación familia-escuela: el uso de las TIC en los centros de primaria". Revista Electrónica Interuniversitaria de Formación del Profesorado, 19(1), pp. 73-83.

MINISTERIO DE EDUCACIÓN (2015). Política Nacional de Convivencia Escolar 2015/2018. Santiago, Chile.

MINISTERIO DE EDUCACIÓN (2002). Política de participación de madres, padres y apoderados/as en el sistema educativo. Santiago, Chile.

MUÑOZ, C., AJAGAN, L., SÁEZ, G., CEA, R., LUENGO, H. (2013). "Relaciones dialécticas antagónicas entre la cultura escolar y la cultura familiar de niños y niñas de contextos vulnerables". Universum, 28(1), 129-148.

RAZETO, A. (2016). "El involucramiento de las familias en la educación de los niños: Cuatro reflexiones para fortalecer la relación entre familias y escuelas". Páginas de Educación, 9(2), pp. 184-201. Recuperado de: http://www.scielo.edu.uy/ scielo.php?script=sci_arttext\&pid=S16887468 $2016000200007 \& \operatorname{lng}=e s \& t \operatorname{lng}=e s$

REAL ACADEMIA ESPAÑOLA. (2017). Diccionario de la lengua española (22. aed.). Recuperado de: http://www.rae.es/rae.html

SCHILLING, C. (2015). "La construcción de nuevas interacciones entre familia y escuela: avanzando hacia una perspectiva comunicativa del espacio escolar". En Nogués y Precht (eds.) Nuevas formas de relación en la escuela: reflexionar y transformar. Pp. 195-214. Santiago: Universidad Santo Tomás - RIL.

VIGO, B., DIESTE, B. Y JULVE, C. (2017). "Discursos sobre participación de las familias en la escuela y éxito escolar". En Garreta, J. (Coord.) Familias y escuelas: discursos y prácticas sobre la participación en la escuela, pp. 149 - 162. Madrid, España: Ediciones Pirámide. 